\title{
Feeding habits and temporal variation of diet composition of fish larvae (Osteichthyes: sparidae) in the Sungai Pulai seagrass bed, Johore, Peninsular Malaysia.
}

\begin{abstract}
Diet composition of most common fish larvae of family Sparidae was studied in the Sungai Pulai seagrass bed of Gelang Patah South Western part of Johor, Peninsular Malaysia from December 2007 to May 2008. Larvae were collected by subsurface towing of a bongo net. In situ hydrographic parameters were recorded during the sampling cruises. Stomachs were removed from a total of 80 Sparidae specimens during the study period and the stomach contents were examined. Analysis of prey in the stomach showed 24 important food items belonging to 8 major groups: phytoplankton, zooplankton, algae, insects, plant like matter, decapod appendages, debris and unidentified matters. The predominant food items found in the stomach were phytoplankton $(60.85 \%)$. This was followed by algae $(11.73 \%)$, zooplankton $(9.35 \%)$, plant matters $(7.84 \%)$, debris $(4.60 \%)$, insects $(2.84 \%)$, unidentified matters $(1.96 \%)$ and decapod appendages $(0.82 \%)$. Habitat in situ temperatures were recorded at $26.92-30.83^{\circ} \mathrm{C}$ (Mean $\pm \mathrm{SD}, 28.60 \pm 1.38$ ); Dissolved oxygen ranged from 4.73 to $6.24 \mathrm{mg} \mathrm{L}-1$ (5.56 \pm 0.53) and the salinity fluctuation was between 29.37 and $33.68 \mathrm{ppt}$ (31.31 1.68$)$. Among the food items, phytoplankton was the first rank by Simple resultant index $(60.85 \%)$ followed by algae $(11.73 \%)$. Therefore, it could be concluded that the fish larvae of family sparidae are mainly herbivorous.
\end{abstract}

Keyword: Feeding habits; Fish larvae; Seagrass; Peninsular Malaysia. 